\title{
QUANDO OS PROFESSORES ESCOLARIZAM OS FILHOS NA REDE PÚBLICA DE ENSINO: DA INEVITABILIDADE À COLONIZAĈ̣̃O ${ }^{1}$
}

\author{
Marlice de Oliveira e Nogueira* \\ Universidade Federal de Ouro Preto (UFOP), Ouro Preto - MG, Brasil \\ Maria Alice Nogueira** \\ Universidade Federal de Minas Gerais (UFMG), Belo Horizonte - MG, Brasil
}

RESUMO: Este texto traz resultados de uma pesquisa que buscou compreender o impacto do exercício da profissão docente na vida escolar dos filhos por meio da análise das práticas educativas de famílias em que, ao menos, um dos genitores é professor. Do universo mais abrangente de uma pesquisa que investigou, em um município do interior de Minas Gerais, 40 famílias através da realização de entrevistas semiestruturadas com pais professores e seus filhos $(\mathrm{N}=80)$, este artigo examina uma subamostra de sete famílias cujos pais professores escolarizavam os filhos na rede pública de Educação Básica. Além da evidência de um "efeito" pai professor na vida escolar dos filhos, os resultados obtidos indicam que pais professores desenvolvem um processo de "colonização" da escola, fazendo com que ela "funcione" a favor da escolarização de seus filhos, intervindo diretamente nas instituições de ensino para prevenir e compensar as supostas consequências de uma escolarização na rede pública.

Palavras-chave: Pais professores. Relação família-escola.

WHEN THE TEACHERS SCHOOL THE CHILDREN IN THE PUBLIC SCHOOL: FROM INEVITABILITY TO COLONIZATION

ABSTRACT: This text presents results of a study that sought to understand the impact of belonging to the teaching profession in the school life of children through the analysis of educational practices in families where at least one parent is a teacher. Based on a larger study that investigated 40 families in a municipality in Minas Gerais, through the application of semistructured interviews with teacher-parents and their children $(N=80)$, this article examines a subsample of seven families who sent their children to

http://dx.doi.org/10.1590/0102-4698153689

Elocation-id - e153689

"Doutora em Educação pela Universidade Federal de Minas Gerais. Professora Adjunta do Departamento de Educação da Universidade Federal de Ouro Preto. Pesquisadora do Núcleo de Estudos Sociedade, Família e Escola (NESFE-DEEDU-UFOP). E-mail: < nogueira_mar@uol.com.br >.

"Doutora em Ciências da Educação pela Universidade de Paris V. Professora Titular do Departamento de Ciências Aplicadas à Educação da Faculdade de Educação - Universidade Federal de Minas Gerais. Pesquisadora do Observatório Sociológico Família Escola (OSFE-FAE-UFMG). E-mail: <malicen@terra.com.br > . 
public schools. Besides enabling the identification of evidence of a teacherparent "effect" on the school life of children, the results indicate that teacher-parents develop a process of "colonization" of the educational setting, making the school "work" for the education of their children, intervening directly in schools to prevent and compensate for the possible consequences of the school belonging to the public system.

Keywords: Teacher-parents. Family-school relation.

\section{INTRODUÇÃO}

Haveria alguma especificidade nos modos como paisprofessores administram a escolarização de seus filhos? Esta foi a questão enfrentada por NOGUEIRA (2011) por meio de uma pesquisa realizada no município de Itaúna, no interior de Minas Gerais, envolvendo, em uma primeira etapa, um universo 114 pais e mães professores/as do Ensino Fundamental e, em uma segunda, uma subamostra de 40 famílias, abarcando um conjunto de dados advindos de 80 entrevistas semiestruturadas com pais/mães e filhos/ filhas em idade escolar (6 a 14 anos $)^{2}$. A hipótese formulada era a da existência de um "efeito pai professor" que impactaria positivamente a vida escolar da prole, por meio dos trunfos adquiridos no exercício cotidiano da profissão, em particular o conhecimento amplo e profundo do funcionamento do universo da escola, e o desenvolvimento de disposições e competências para operar com maior eficácia sobre ele.

Com efeito, pesquisas realizadas, desde os anos 1970, sobre a escolha do estabelecimento de ensino pelas famílias indicam que a atuação dos pais professores apresenta certas peculiaridades tanto do ponto de vista estrito dessa escolha quanto no que concerne, mais amplamente, ao conjunto de estratégias desenvolvidas ao longo da trajetória escolar dos filhos (GOODSON, 1975; BALLION, 1982; BALLION, 1986; WILSON, 1989; GISSOT; HÉRAN; MANON, 1994; DURU-BELLAT, 1996; BOYER; DELCLAUX, 1995; GEWIRTZ; BALL; BOWE, 1995; HATCHER, 1998; LANGOUET; LEGER, 2000; LASEK, 2007). Em comparação com outras categorias socioprofissionais, tais pesquisas apontam os pais professores como os portadores das mais altas ambições escolares para os filhos e como os melhores "estrategistas" por desenvolverem e implementarem estratégias de "iniciados" ao longo do processo de escolarização dos filhos. Além disso, possuem um grande trunfo decorrente da ocupação exercida e do próprio ambiente de trabalho: a inserção em uma rede de solidariedade e de relacionamentos no mundo escolar que os provê de um capital social ${ }^{3}$ facilitador do desenvolvimento de estratégias consideradas "eficazes". 
As investigações realizadas por Pedro Silva (2003, 2006a, 2006b, e 2007a, 2007b) sobre a relação família-escola em Portugal também destacam o papel desempenhado pelos pais professores. Embora o autor tenha por foco a atuação específica de pais professores como membros de órgãos de gestão escolar (líderes ou participantes de Associações de Pais, por exemplo), seus trabalhos atingem um alcance mais amplo, visto que colocam em destaque a "condição híbrida" desses pais, na medida em que são chamados a assumir o duplo papel, de pai e de professor. Ainda em Portugal, Vieira e Relvas (2005) realizaram uma pesquisa qualitativa sobre as condições de trabalho dos professores portugueses abordando o modo como as experiências vividas na profissão podem impactar positiva ou negativamente a vida familiar e vice-versa. Os autores chamam a atenção, particularmente, para os benefícios advindos de seu extenso conhecimento sobre o mundo escolar.

No Brasil, ainda pouco sabemos sobre a questão. Mas os trabalhos de Santana (2005), Reis (2006) e Andrade (2006) já em meados da década passada, apontavam os pais que exercem a docência como os mais aptos a escolher a escola dos filhos, revelando ainda dados que demonstram que a grande maioria dos professores opta pela escola particular no momento de escolarizar os filhos no nível da Educação Básica.

Mais recentemente, Costa (2011) e Barg (2011) se propuseram a investigar mais especificamente o desempenho escolar de filhos de professores, utilizando-se de dados estatísticos do sistema de ensino francês (INSEE, 2003) ${ }^{4}$. A tese de doutoramento de Annie Lasne da Costa demonstrou a existência de um "efeito pai professor" que influencia positivamente a vida escolar dos filhos, na medida em que é nesse grupo social que se concentram as disposições mais favoráveis a incitar ao êxito escolar. O trabalho de Katherine Barg (2011) examina igualmente esse favorecimento, constatando que os filhos de professores obtêm melhores resultados em relação a seus pares provenientes de outros grupos ocupacionais nos testes padronizados da escola secundária francesa. Esses dois trabalhos ressaltam a carência de estudos nesse sentido e clamam por investigações que adentrem a vida familiar a fim de desvelar os microprocessos que respondem pelo fenômeno constatado.

Tentando, modestamente, responder a tal chamamento, propomos aqui a análise de um dos casos resultantes da pesquisa acima mencionada, realizada no município de Itaúna: aquele referente ao pequeno grupo de sete famílias (num universo das 40 entrevistadas) que escolarizam seus filhos em escolas da rede pública (estadual ou municipal) de Educação Básica, lembrando que a grande maioria 
$(\mathrm{N}=33)$ da população investigada opta pela rede privada de ensino ${ }^{5}$.

Para compreender as práticas educativas e estratégias de escolarização desse grupo de sete famílias, utilizamos dados oriundos de 14 entrevistas semiestruturadas realizadas com um pai professor e seis mães professoras, assim como com sete de seus filhos/as. Veremos que, nessas famílias, o "efeito pai professor" apresenta variações e particularidades que advêm de diversos fatores, tais como: (i) condições socioeconômicas pouco favoráveis, levando à inevitável opção por matricular os filhos na escola pública; (ii) posse de informações sobre o mundo escolar e utilização de diferentes formas de intervenção direta no estabelecimento de ensino frequentado pelos filhos ${ }^{6}$; (iii) existência de divergências entre os cônjuges quanto às práticas educativas familiares e o exercício da autoridade parental. A conjunção desses fatores torna bastante particular a experiência escolar das crianças e dos adolescentes pertencentes a esse grupo de famílias.

Este artigo está organizado em quatro seções. $\mathrm{Na}$ primeira delas, apresentamos as sete famílias investigadas, suas características demográficas, socioeconômicas, culturais e profissionais. $\mathrm{Na}$ segunda, tratamos das dinâmicas familiares e dos projetos longevos de escolarização desenvolvidos pelos pais professores. Em seguida, na terceira seção, são analisadas as evidências de um processo de "colonização" levado a cabo pelos pais professores e derivado da inevitabilidade de escolarizar os filhos na rede pública. Por fim, as considerações finais tratam de tecer fios que permitam discutir e compreender a complexidade do "efeito pai professor" em famílias de docentes que escolarizam os filhos na rede pública de Educação Básica.

\section{OS PAIS PROFESSORES E SUAS FAMÍLIAS}

As sete famílias entrevistadas são compostas por seis mães professoras e apenas um pai professor. Com idade variando entre 36 e 45 anos, as seis mães declaram manter união estável constituindo famílias biparentais, e o único sujeito do sexo masculino é membro de uma família recomposta ${ }^{7}$ e mantém, sob sua guarda, os dois filhos da primeira união. Trata-se de famílias com prole reduzida com dois filhos em sua maioria, o que representa, para elas, a busca de "reproduzir, através da descendência, sua posição - dinamicamente definida - na estrutura social, ou seja, de realizar o futuro a que se está destinado" (BOURDIEU, 2008, p. 311). A investigação aprofundada dessas famílias evidenciou elementos que possibilitaram refinar a análise, levando-se em conta a relação entre as condições materiais de existência, o capital escolar adquirido e as estratégias de fecundidade dos pais. 
A renda familiar mensal do grupo variava no momento da pesquisa (2009/2010) entre 1.900 e 3.800 reais (entre três e sete salários mínimos à época), o que situa as famílias no interior da chamada "nova classe média" ou classe "C" para alguns economistas (NERI, 2011). Variáveis como o tipo de moradia e sua localização são apontadas por Bourdieu (2008), entre outros, como fatores de distinção e contribuem para a caracterização e classificação social das famílias. A identificação dessas variáveis tornou-se possível porque todas as entrevistas foram realizadas no domicílio dos pais professores.

Três das sete moradias estão localizadas em bairros com condições estruturais e sociais que os classificam como "bairros de classe média". As outras quatro moradias estão localizadas em três diferentes bairros da periferia da cidade que acolhem um público majoritariamente definido, pelos pais professores entrevistados, como pertencente às classes populares ${ }^{9}$. Quanto ao tipo de moradia e a seus aspectos internos, cinco famílias residiam em imóveis próprios, adquiridos mediante financiamento por programas do governo federal; um pai professor herdou o imóvel da família de origem, e duas famílias moravam em casas alugadas. As moradias visitadas não eram amplas nem luxuosas, mas apresentavam uma arrumação cuidadosa. Apesar da simplicidade dos móveis, havia uma harmonia agradável na organização do ambiente. Apenas em duas das moradias (uma casa alugada e um imóvel próprio), essa "harmonia" não foi constatada: numa delas, a sala de estar funcionava também como local de trabalho para o cônjuge que exercia a profissão de vendedor, transmitindo aos que ali entravam uma sensação de desordem. As moradias revelavam, em sua totalidade, a preocupação dos pais com o desenvolvimento das tarefas escolares: apesar de sua reduzida superfície, o quarto dos filhos abrigava sempre um cantinho para estudo, contendo uma mesa pequena e uma estante com livros de literatura e enciclopédias. Em cinco das sete moradias havia um computador, ora no quarto dos filhos, ora no quarto do casal.

Em relação à origem social, o pai e as seis mães possuem progenitores com: (i) baixo nível de instrução: pais e mães não ultrapassaram o Ensino Fundamental incompleto; (ii) tendo exercido, em sua vida ativa, ocupações classificadas como subalternas (SCALON, 1999; PASTORE; SILVA, 2000). Pelo fato de deter um diploma de curso superior e de exercer a profissão docente, é certo que os pais professores investigados sofreram um processo de mobilidade social ascendente em relação à posição ocupada por seus progenitores. Mas essa vantagem relativa deve ser analisada levando-se em conta as variáveis relativas à ocupação e ao nível de instrução de seus cônjuges. 
A tendência a casamentos regressivos ${ }^{10}$, tanto do ponto de vista ocupacional quanto no que tange ao nível de instrução é marcante no grupo. As seis mães professoras mantêm união estável com cônjuges menos escolarizados e que exercem ocupações classificadas como de nível médio ou inferior (SCALON, 1999; PASTORE; SILVA, 2000). Somente o pai professor é casado com cônjuge possuidor de diploma de curso superior. Essa tendência afeta de modo marcante as famílias desse grupo, compondo, juntamente com outros elementos, as suas condições materiais e simbólicas de existência. A ascensão social e econômica, almejada pela conquista de uma escolarização mais longa, parece não ter sido totalmente efetivada.

Cumpre assinalar que casamentos regressivos também foram observados no universo mais amplo das mulheres professoras que responderam ao questionário inicial da pesquisa (mais precisamente em $77 \%$ do total de 101 professoras), o que leva a supor que, em seu conjunto, as professoras não dispunham, no momento do matrimônio, de outros trunfos que pudessem ser associados a seu alto capital escolar, e não se casaram com homens com formação similar ou superior à sua porque, ao seu dote escolar, não puderam agregar outros atributos, como, por exemplo, uma origem social favorecida. De acordo com Singly (2000), embora a ação dos diplomas - numa sociedade em que o capital escolar é altamente valorizado - tenha papel determinante na fixação de valores aos indivíduos, essa ação não tem peso suficiente para eliminar a atuação de outros capitais representados por recursos materiais e simbólicos.

No caso das seis mães professoras do grupo aqui focalizado, todas casadas com cônjuges menos escolarizados, o exame do período de realização do curso de graduação e do tempo de união estável demonstra que realizaram seus estudos universitários em período posterior ao casamento. Ressalta-se que esse fenômeno da realização de estudos superiores após o matrimônio pode ser interpretado segundo a hipótese de Batista (2007) de que o "caráter extemporâneo" da formação universitária sinalizaria que elas não realizaram casamentos heterogâmicos e descendentes, do ponto de vista do nível de instrução, mas que os casamentos se tornaram heterogâmicos. Ainda seguindo as trilhas analíticas desse autor - em seu estudo sobre os benefícios econômicos e sociais do "dote escolar" e suas relações com as estratégias matrimoniais de professoras de Português -, é possível supor que essas mães professoras tenham até mesmo se beneficiado de um casamento que lhes proporcionou as condições materiais e simbólicas para o acesso e a obtenção do diploma do curso superior. 
Assim, o matrimônio teria possibilitado que elas tivessem não somente as condições econômicas para a realização dos estudos universitários, mas também um suporte material e simbólico proporcionado pela situação conjugal, como ilustram os seguintes depoimentos: "eu só pude estudar porque meu marido ficava com os meninos, senão seria impossível"; "ah...estudar não foi fácil, mas o J. (esposo), mesmo não tendo estudo, me ajudou demais, ele olhava os meninos, fazia o jantar e ainda me buscava na faculdade..."; e ainda, "puxa...você me fez lembrar agora...o M.(esposo) não entendia muito bem porque eu queria tanto estudar... mas mesmo assim me ajudou muito mesmo, me emprestava dinheiro, ficava com a P. (filha) que ainda era bebê, ele não entendia, mas sem ele eu não teria conseguido".

Sem nenhuma exceção, os sete pais professores realizaram os Ensinos Fundamental e Médio nas redes públicas de ensino: em seis casos em escolas da rede estadual; e, em um caso, os anos iniciais do Ensino Fundamental foram realizados em escola municipal rural, com os graus subsequentes tendo sido cursados em escola estadual na área urbana do município. No nível do Ensino Superior, entre as sete famílias, o único pai professor diplomou-se em Ciências Biológicas, três mães professoras em Letras, e as outras três em Matemática, Geografia e Pedagogia. A graduação foi cursada por todos em apenas duas instituições de Ensino Superior privadas, localizadas na cidade de moradia ou em seu entorno. A trajetória escolar desses pais professores, em forma de "circuito vicioso" (Educação Básica em instituições públicas e Ensino Superior em instituições particulares de menor prestígio acadêmico) ${ }^{11}$, marcou fortemente a vida desses sujeitos. Desprovidos, na origem, de maiores recursos financeiros, e constrangidos a uma formação superior em instituições de reduzido prestígio, têm suas vidas fortemente impactadas por desvantagens, ao mesmo tempo, sociais e profissionais.

À época da entrevista, cinco mães professoras lecionavam somente na rede pública, e os outros dois (um pai e uma mãe), em escolas das redes pública e particular ao mesmo tempo. Todos detinham mais de 10 anos de experiência docente, sendo que cinco deles haviam sido efetivados, mediante concurso, na rede estadual de ensino; e os outros dois trabalhavam como contratados nas redes estadual e municipal. Todos os sete sujeitos cumpriam uma carga horária semanal de trabalho igual ou superior a 32 horas/aula.

A análise de seus gostos e de suas preferências culturais ajuda a definir o lugar ocupado por essas famílias na hierarquia social e cultural, para além de dados como a renda ou a posse de bens de consumo que, por si só, não conseguem revelar todas as nuanças de um perfil sociocultural. Se, do ponto de vista socioeconômico, os 
sete pais professores podem ser classificados como pertencentes às frações inferiores da classe média brasileira, dados sobre a utilização do seu tempo livre e atividades de lazer, sobre suas escolhas e práticas culturais cotidianas (leitura, televisão, cinema, teatro, música etc.) contribuem para recompor com mais acuidade seu estilo de vida e, sobretudo, para estabelecer relações entre ele e as práticas educativas que desenvolvem no âmbito da vida doméstica.

Nessas famílias, não é comum a frequência a cinema, teatro, espetáculos musicais ou de dança. Os sete sujeitos declaram nunca ter frequentado museus ou centros culturais. Mas a baixa ou nula frequência dos professores a eventos culturais não significa que não reconheçam sua legitimidade. No entanto, nos termos de Bourdieu, esse "reconhecimento" se dá de modo apartado do "conhecimento" (o qual suporia a frequentação desses espaços) ${ }^{12}$, porque os imperativos da existência cotidiana forçam esses sujeitos à "escolha do necessário", aquela que os guia em suas escolhas culturais. No entanto - cientes da (curta) mobilidade social conquistada em relação às suas famílias de origem -, eles vivem uma tensão entre a "escolha do necessário" e suas disposições de "boa vontade cultural" (BOURDIEU, 2008, p. 355).

Tal tensão pode, por exemplo, ser identificada em suas ações de escolha do estabelecimento de ensino para os filhos, bem como na elaboração de estratégias relacionadas à escolarização deles. Em todas as sete famílias, os filhos estudam (e estudaram durante toda a trajetória escolar pregressa) em estabelecimentos de ensino básico públicos pertencentes à rede municipal. Suas atividades extraescolares são menos intensas do que aquelas verificadas entre as camadas médias altas (NOGUEIRA, 1995): em apenas um caso, os filhos frequentam um curso livre de língua estrangeira; em outro, o filho estuda informática em curso particular. Em suma, os gastos com a escolarização se resumem, grosso modo, à aquisição do material escolar e, em alguns poucos casos, à contratação de aulas particulares, além do inexpressivo extraescolar, como se viu.

No entanto, esses pais vivem desconfortável e constrangidamente sua impossibilidade de proporcionar aos filhos os mesmos recursos educacionais que observam nas frações mais bem providas das camadas médias. Em tom de lamento e quase como se desculpando, confessam nas entrevistas que "pesa muito não dar o que eles merecem, ou melhor, o que eles precisam de verdade", "eu penso sobre isso, eu sei que eles precisam de mais, isso me incomoda, você entende? "Mas olha só, se eu não posso fazer coisas que eu sei que deveria fazer, vou tentando fazer outras pra compensar, sabe?". Ou ainda, como podemos ver no trecho abaixo: 
O inglês, por exemplo, o inglês da escola é uma falácia. A única coisa que eles ensinam lá $e$ the book on the table [risos] e o verbo to be o tempo todo. Brincadeira! Mas é ruim mesmo. Eu falo que, se for depender do inglês lá, não passa no vestibular, não. Então, o ideal é que eles façam aula de inglês. Eu deixei pra colocar eles no inglês quando estiverem no $\sigma^{\circ}$ ano. Eu pensei, se colocar agora, eles são pequenos [filhos de dois e oito anos] e eu não sei se dou conta de deixar até o vestibular. Então, colocar pra depois tirar é pior. Eu acho que nós vamos colocar eles lá pela sexta série mesmo. Tem hora que eu me sinto mal com isso, mas fazer o quê? A gente vai ajustando aqui e ali, a vida é assim. (Pai professor)

Essa situação de cindidos e tensionados faz com que sentimentos de angústia e relativa impotência sejam igualmente desenvolvidos, sentimentos que afetam diretamente as dinâmicas familiares e, consequentemente, suas práticas e estratégias de escolarização.

\section{DINÂMICAS FAMILIARES E EXPECTATIVAS DE LONGEVIDADE ESCOLAR}

Nas sociedades ocidentais, no curso das últimas décadas, a interdependência - historicamente constituída - entre escola e família vem se reforçando cada vez mais (SINGLY, 2004; SILVA, 2003; NOGUEIRA 2005, 2006). No caso das famílias pesquisadas, essa realidade interativa torna-se ainda mais acentuada e complexa porque $\mathrm{o}$ pai é professor e o professor é pai. A pesquisa de Vieira e Relvas (2005) demonstrou os efeitos dessa dupla condição na vida dos professores e de suas famílias. Segundo as autoras, existem fatores familiares que produzem impactos na vida profissional dos professores e, vice-versa, fatores de sua vida profissional que influenciam a vida familiar. No segundo caso, os impactos são, em boa parte, negativos, alterando o cotidiano da vida em família (excesso de trabalho, pouco tempo para os filhos, envolvimento emocional com os alunos, baixos salários, indisciplina dos alunos). Mas as autoras portuguesas descortinam também aspectos positivos, tais como: os "conhecimentos vários" obtidos no exercício da profissão, as atitudes de tolerância adquiridas no convívio com os alunos, a relação com os colegas de profissão e, até mesmo, o favorável sistema de férias etc. Entre os conhecimentos e atitudes construídos pelos professores - e que afetam sua vida familiar - as autoras dão grande ênfase ao modo de exercício da autoridade parental sobre os filhos, o que também se sobressaiu em nossa análise das dinâmicas internas das famílias investigadas.

Constatamos que as relações de autoridade nelas estabelecidas têm seu pilar na figura do progenitor professor, e se assentam, via de regra, no diálogo e na negociação. Entretanto, esse modo de exercer a autoridade, próprio às seis mães professoras, entra em confronto com o de seus cônjuges, criando uma fonte de tensão no seio das 
famílias ${ }^{13}$. Podemos supor que o embate produzido no interior das famílias é resultado da distância entre o modo de socialização no trabalho vivenciado pela mãe e aquele vivenciado pelo pai. Embora tanto os pais quanto as mães - dada sua origem social - tenham provavelmente sido socializados num modelo familiar "posicional" (BERNSTEIN, 1960, 1973), em que as áreas de decisão e julgamento estão formalmente definidas e o exercício da autoridade é calcado no estatuto formal de cada membro familiar, os conhecimentos produzidos e as experiências vivenciadas no trabalho contribuíram para reforçar (no caso dos maridos) ou transformar (no caso das mães professoras), essa lógica socializadora, ou seja, esse modelo educativo.

Nesse sentido, o exercício da docência - que implica um trabalho complexo em que os sujeitos precisam utilizar a linguagem como forma de convencimento e de construção do mundo, na manipulação de signos e símbolos, e na tomada de decisões baseada nas individualidades - propiciou às mães professoras formular práticas educativas mais voltadas para a construção da autonomia. Ao contrário, a experiência de seus cônjuges em profissões que demandam atividades rotineiras e mecanizadas (metalúrgico, operário, motorista) contribuiu para reforçar práticas educativas calcadas na obediência e na ordem (KHON, 1977; BERNSTEIN, 1960, 1973).

Assim, num modelo fundado na "comunicação aberta" e na "orientação para a pessoa ${ }^{14 "}$, esses pais educam seus filhos através de uma "interação dinâmica", modo de comunicação comum às classes médias, conforme já explicitado acima. Enquanto as mães professoras dedicam-se intensamente à tarefa de neutralizar, em alguma medida, a influência (vista por elas como negativa) do modo autoritário de educar próprio dos maridos, na família do único pai professor parece haver uma maior sintonia entre as atitudes do pai e de sua esposa, ambas baseadas em um modo de "comunicação aberta"15.

Todavia, exercer a autoridade através do diálogo e da negociação não implica abster-se de manter estrita vigilância sobre a vida dos filhos. Os pais e as mães exercem um forte controle sobre suas atividades lúdicas e saídas com os grupos de amigos, por exemplo. Mesmo permitindo que eles "brinquem na rua com vizinhos", isso não se realiza sem a permissão direta dos pais e o controle do tempo e das companhias (com qual amigo, quando, onde e por quanto tempo). $\mathrm{O}$ modo de socialização familiar, neste caso, é um modo "orientado para a pessoa”, porquanto os pais centralizam, neles próprios, a educação dos filhos e não permitem que outras agências de socialização (como os pares, outras famílias ou, até mesmo, a escola) o façam. E mesmo 
que outros "atores" entrem em cena (como avós, irmãos ou os amigos), os pais não se abstêm do controle sobre a influência que tais atores possam exercer sobre a educação dos filhos.

Além disso, esses pais exercem um trabalho contínuo para imbuir os filhos de "disciplina e esforço". Incentivam e exigem deles uma dedicação plena aos estudos e às tarefas escolares, e lutam para que eles desenvolvam um senso de autodisciplina.

Esse traço foi igualmente verificado no conjunto maior das 40 famílias investigadas (NOGUEIRA, 2011, 2013). No entanto, quando contrastadas com o restante das famílias do universo pesquisado, nas sete famílias aqui estudadas, tanto o pai quanto as seis mães professoras reduzem suas exigências quanto à construção dessa autodisciplina porque: (i) têm plena consciência do mais baixo grau de exigência da escola pública e (ii) dão-se conta de que, por essa mesma razão, seus filhos se sobressaem em relação aos seus colegas de turma. Por outro lado, são cientes da exígua possibilidade de que, mais tarde, eles ingressem nas universidades públicas, altamente competitivas.

Quando comparados com outros grupos de pais professores (NOGUEIRA, 2011), esses sete pais - detentores de amplo conhecimento dos limites de uma escolarização na rede pública brasileira - modulam suas expectativas acadêmicas (e profissionais) para os filhos, ajustando-as ao "máximo do possível". Porém, apesar da alta carga horária semanal de trabalho ${ }^{16}$, eles desenvolvem, ao mesmo tempo, estratégias educativas tanto de antecipação dos ritmos escolares (tais como: alfabetizar previamente a criança em casa, antecipar conteúdos previstos no currículo), quanto de compensação de possíveis deficiências, como se vê no depoimento dessa mãe-professora: "olha, eu gosto de sempre dar um reforço pra ele, assim, ir ajudando em tudo que ele tem dificuldade, é meu papel não é? Eu queria fazer mais, eles precisam de mais. Mas é isso que eu consigo fazer...".

Assim, dilacerados pela consciência de suas limitações econômicas e pelo conhecimento amplo do funcionamento do mundo escolar e das leis que regem o sucesso profissional, em particular a do o peso da longevidade escolar na vida adulta, esses pais vivenciam uma profunda angústia pessoal e profissional, expressa em seus depoimentos. Eles vivem uma tensão entre o forte desejo de investir mais na escolarização dos filhos ("eu precisava ajudar mais", "o ideal seria colocar na aula de inglês", "eu quero um dia poder colocar na escola particular") e a angústia profunda de saber que só podem realizar o "mínimo". Assim, se veem envoltos numa dinâmica entre as "aspirações subjetivas" e as "chances objetivas" que fixa limites 
simbólicos para a concretização de suas aspirações de mobilidade social pela via do sucesso escolar dos filhos.

Mesmo que as sete famílias desse grupo não sejam completamentehomogêneas no tocanteàs condições socioeconômicas e às expectativas em relação à escolarização, o fato é que todas elas aspiram estudos longos para os filhos: "Eu sonho que eles possam fazer uma faculdade", "é claro que eu almejo que eles façam a faculdade", "ah! a faculdade está nos nossos planos, eles vão fazer uma faculdade", "é claro que eu quero que eles vão o mais longe possível, que façam universidade e até um mestrado", são expressões correntes nos discursos parentais.

Para isso, asceticamente, recorrem à estratégia de poupar recursos financeiros para que o filho possa "fazer uma faculdade", "o Ensino Médio numa escola particular", ou "um curso de inglês". Possuidores de reduzido capital econômico, esses pais necessitam de uma espécie de "acumulação" inicial, um princípio de economia, que busca compensar a escassez desses capitais (BOURDIEU, 2008) Assim, "juntar dinheiro para fazer uma faculdade" significa vislumbrar a realização de estudos longos tão almejados por essas famílias, apesar da certeza da desvantagem inicial dos filhos em razão de frequentarem a escola pública.

\section{INEVITABILIDADE DA ESCOLA PÚBLICA E PROCESSOS DE “COLONIZAC̣ÃO”}

O fato de que é inevitável matricular os filhos na escola pública, por um lado, e a consciência - advinda da própria experiência docente nessas instituições - de que tal condição educacional não favorece o acesso a instituições de ensino superior de prestígio, por outro, conduzem esses pais a desenvolverem estratégias para minimizar tal efeito, tentando assegurar um bom desempenho na Educação Básica e o acesso ao curso superior, ainda que em instituições particulares e de menor reputação.

Mais próxima de uma "não escolha" (BOURDIEU, 2008), a opção pelo estabelecimento de ensino público nem por isso se dá ao acaso. As famílias elaboram, dentro de seu universo de possíveis, uma classificação objetiva e simbólica de um leque de estabelecimentos, e optam por aquele que melhor atenda a seus objetivos e que possa, a seu ver, atenuar as consequências negativas, para a formação dos filhos, das deficiências atribuídas à rede pública.

Em seu ato de escolha, esses pais professores se servem do "senso do jogo", ou seja, do conhecimento prático e das disposições que construíram no exercício da profissão, levando em consideração os seguintes fatores, para além da preferência pela instituição escolar 
em que eles próprios atuam: a) informações sobre os professores e o trabalho que desenvolvem na escola, b) informações sobre a gestão da escola, c) informações sobre a equipe de educadores e sobre as características dos alunos, d) informações sobre o material didático utilizado, d) informações sobre o número e a composição das turmas, e) percepção do clima da escola (disciplina, regras de convivência etc.).

Nos quatro casos (três mães e um pai) de opção por escolarizar o filho na mesma escola em que atuam profissionalmente, os genitores professores, além do amplo acesso a informações diretas e contínuas sobre o estabelecimento, tem a possibilidade de intervir diretamente, quando necessário, na vida escolar do filho, exercendo forte vigilância e controle sobre o que ocorre na escola, facilitados inclusive pelos contatos ali estabelecidos. As três outras mães que escolarizaram seus filhos em estabelecimento de ensino diferente daquele em que lecionam o fizeram por julgar que este último apresentava grande precariedade e insuficiência no plano da qualidade do ensino e, por isso, optaram por uma escola pública que, de um modo geral, gozava, entre os professores, de uma imagem mais positiva.

Em suma, ao escolher o estabelecimento de ensino para os filhos, esses pais professores não adotam critérios exteriores ao processo de formação ou, em outros termos, critérios de conveniência prática ou "funcionais" (localização, facilidade de acesso, etc.), que são os mais usuais entre as famílias das camadas populares. Ao contrário, aproximam-se muito mais das condutas "avaliatórias" (BALLION, 1982, 1986) - típicas das camadas médias e superiores -, que se assentam sobre aspectos internos ao processo pedagógico, como a competência dos professores e a gestão da escola, entre outros. Sua "escolha do necessário", nos termos de Bourdieu (2008) ${ }^{17}$, se dá, portanto, dentro de parâmetros bem definidos, entre a escola na qual exercem a docência e o estabelecimento público que consideram ser o "melhor" do município.

$\mathrm{Na}$ condição de usuários da rede pública, os pais desenvolvem um conjunto de estratégias de intervenção direta na escola, as quais configuram um processo de "colonização" do ambiente escolar. Esse termo tem sido utilizado por sociólogos da educação como Van Zanten $(2001,2009,2010)$ e Power et al. (2003) para designar as pressões que exercem certas famílias favorecidas no sentido de influenciar, a seu favor, as políticas (de recrutamento, de enturmação, de conteúdos curriculares etc.) dos estabelecimentos de ensino públicos onde matricularam os filhos.

Segundo Van Zanten (2010), as famílias francesas de classe média realizam suas escolhas em matéria de estabelecimento escolar tendo como eixo estruturante da escolha o evitamento de um público 
escolar considerado "diferente de si" e, ao inverso, a preferência por escolas que possibilitem aos filhos uma convivência com outros "iguais a si”. Para isso, desenvolvem estratégias que visam obter informações privilegiadas sobre as escolas, estabelecendo contatos estreitos com informantes em potencial (outros pais, diretores, professores) e criando canais de confiança, por meio dos quais obtêm informações suficientemente "quentes", e nem sempre oficiais, que possibilitam a hierarquização dos estabelecimentos escolares e uma escolha eficaz. Eles também participam ativamente dos órgãos escolares coletivos oficiais, como conselhos de classe e associações e desenvolvem formas de intervenção na escola, facilitadas pela cooperação de diretores, agentes escolares e de outros pais, que podem se realizar por duas vias: a) a constituição de turmas escolares que são verdadeiros "territórios fechados" para os filhos, ou seja, turmas, no interior do estabelecimento, que operam uma seleção não apenas escolar, mas, principalmente, étnica e racial e b) intervenção seletiva na escola exercida pelos membros dos conselhos escolares e associações de pais por meio de uma vigilância acirrada em relação aos professores e ao funcionamento da escola e seus processos curriculares e educacionais.

$\mathrm{Na}$ esteira desses autores, é possível afirmar que os pais professores se envolvem em um intenso processo de colonização da escola, evidenciado por uma presença intensiva no ambiente escolar, uma forte vigilância do cotidiano da escola e da sala de aula, um visível controle material e simbólico das situações de interação com professores, especialistas, diretores e, mais amplamente, dos contextos de socialização das crianças, como indicam os relatos de duas mães professoras:

Bom, eu trabalho na escola, eu conbeço os professores, os alunos, a diretora também, a supervisora, conbeço tudo. No ano passado, ele [o filho] teve um probleminha no $5^{\circ}$ ano com a professora. Eu fiquei observando o material dele e vi que tinha muita coisa errada. A professora, infelizmente, não tinha competência mesmo. Eu pedi pra trocar de sala. Eu exigi mesmo e deu certo. Tem essa vantagem conhecer a escola e as pessoas também, a gente pode acompanhar mais de perto.

E mesmo eu não trabalhando na escola, conbeço muita gente que trabalha lá, conheço a diretora. Quando eu levei eles [os filhos] pra lá, eu procurei T. [diretora] e falei aberto. Ela me ajudou muito, me mostrou o livro que eles adotavam. Eu não gostei muito do livro de Português, mas também não era o pior. Mas o livro de matemática era horrivel. Eu falei que o livro era ruim, que não prestava mesmo. Então eles mudaram, pelo menos isso eu consegui.

Lecionando ou não no mesmo estabelecimento em que matricularam o(s) filho(s), a esses pais é facultado ou possibilitado, em maior ou menor grau: (a) escolher a turma e o professor regente que receberá seu filho e trocá-lo de turma quando insatisfeitos, pois acreditam que nas melhores turmas, "os meninos aprendem mais", "a 
aula flui", o professor "consegue ensinar mais" e pode "dar todo o conteúdo"; (b) determinar a posição na sala de aula e a carteira do filho; (c) obter acesso ao material didático utilizado e opinar sobre ele; (d) monitorar as interações entre o filho e seus pares, bem como entre ele e os profissionais da escola, entre outros. Tudo isso é facilitado seja pelo exercício da docência no próprio estabelecimento, seja pelos contatos estabelecidos com outros professores, diretores e outros profissionais da educação ("Eu tenho liberdade de falar com a diretora", "eu sempre vou na direção"). Assim, esse "capital social interno" (VAN ZANTEN, 2009, 2010), através da posse de "informações quentes sobre a escola, é mobilizado pelos pais, a fim de obter o máximo possível de benefícios para os filhos" (VAN-ZANTEN, 2010, p.423).

Os pais professores, nos casos em que escolarizam os filhos nas escolas em que atuam profissionalmente, declaram circular pela escola nos horários de recreio (principalmente) e nos intervalos entre as aulas para acompanhar de perto o "clima da escola" e das turmas em que os filhos se inserem: "eu gosto de andar pela escola... geralmente antes de ir lanchar dou uma passadinha para ver o recreio, ver com quem ele [o filho] tá andando", "Ah, eu fico observando tudo, a disciplina na sala dela [ da filha], se está tudo tranquilo, se tem muita bagunça, passo sempre lá". Eles exercem também um monitoramento diário das atividades pedagógicas propriamente ditas: "não tem jeito, eu preciso ver tudo de perto, procuro saber tudo o que eles vão fazer na semana". "Quando a agenda dele não traz as atividades, eu vou lá e quero saber, eh...tudo o que eles vão fazer, atividade, conteúdo novo, se vai ter prova, essas coisas. Se não fizer isso, a coisa pode descambar, e a gente acaba impondo um pouco o respeito".

De fato, é por meio dessas ações de colonização que esperam mitigar os supostos efeitos negativos de uma escolarização na rede pública, oferecendo aos filhos as melhores condições possíveis para seu desenvolvimento acadêmico e extraindo assim de uma situação inevitável, a maior rentabilidade possível.

No acompanhamento doméstico da escolarização da prole, outro conjunto de estratégias é cotidianamente adotado pelos pais professores, tais como: preparação e aplicação de exercícios e tarefas suplementares às aulas, como forma de preparação para as avaliações escolares; aplicação, em casa, de provas tais como a do ENEM; seleção e coleta de livros didáticos de diferentes disciplinas (em geral doados por colegas de docência) para diversificar o material disponível para estudo e fornecer apoio nos deveres de casa. Assim, se poderia dizer que eles assumem, no interior do lar, um papel claramente professoral, confirmando serem "pais profissionais" (ESTABLET, 1987). 
Apesar desse forte investimento, não se deve esquecer - como vimos na seção anterior - que essas familias trabalham pela construção de uma "autonomia controlada" dos filhos, e esperam que eles se impliquem fortemente nos estudos. Isso significa que é também na mobilização escolar do filho-aluno que os pais depositam suas expectativas de minimização de algumas insuficiências advindas das práticas de monitoramento diário de que são capazes, em razão de sua sobrecarga de trabalho. E tentam compensar essas insuficiências delegando esse encargo a pessoas de "sua confiança", como avós, sobrinhos ou vizinhos. Mas essa delegação não abala a rigidez do enquadramento das tarefas: os filhos não podem deixar de fazer os deveres de casa, que devem ser feitos corretamente e em local apropriado.

Outra preocupação diz respeito à sociabilidade dos filhos, mais precisamente às companhias e aos colegas de escola. Para assegurar um estar "entre iguais", eles tentam interferir, como vimos, na escolha da turma, dos colegas e até mesmo do lugar ocupado na sala de aula, visando minimizar as consequências negativas que podem derivar do convívio com pessoas de outros meios sociais. Oriundos das camadas populares, eles buscam assegurar e proteger suas "conquistas", desenvolvendo estratégias de "fechamento" frente àqueles que consideram "diferentes de si" e companhias "indesejáveis" (VAN ZANTEN, 2010). Assim, a escolha da turma e do lugar na sala de aula - que constitui uma tônica nos depoimentos de todos os pais professores - preenche tanto uma função pedagógica, quanto uma função social de integração a um grupo social, percebido por eles, "como próximos de si" (VAN ZANTEN, 2010), como podemos observar nos dois relatos a seguir:

Eu conheço bem a escola, ela é cheia de problemas, tem muitos alunos que são difíceis, é periferia, você já viu, né? Mas tem muitos meninos bons também. Eu conheço a diretora, sei o jeito dela trabalhar. Vou te dar um exemplo: na hora de fazer as turmas, a diretora sempre me pergunta onde eu quero colocar os meninos, em qual turma. Então, esta liberdade que eu tenho lá me ajuda muito. Eu coloco eles [os filhos] numa turma boa. Então, as coisas ficam mais tranquilas. Eles [os filhos] são muito bons, então, os professores gostam deles. A gente vai tentando fazer o melhor para que eles [os filhos] não fiquem assim tão prejudicados.

Ah...eu vou te falar a verdade... não tenho nem vergonha de dizer...eu escolho a turma em que ele [o filho] vai estudar. Escolho até o lugar de assentar, lá eles fazem mapa da sala. Eu preciso proteger ele [o filho]. Se ele ficar perto de uns meninos dificeis que a escola tem... não dá. Você sabe como é...você conhece também. O bairro é muito barra pesada, eu não quero que eles convivam com esses meninos, então eu vou lá e converso, peço pra colocar ele [o filho] num lugar bom, perto de meninos mais responsáveis.

Todo esse esforço parental parece surtir efeito, pois, no conjunto das sete famílias entrevistadas, não houve, na trajetória escolar dos filhos, nenhum caso de reprovação, e as notas obtidas são 
geralmente bem superiores à média da maioria dos alunos da escola. Para os pais, o desempenho escolar dos filhos varia de bom a ótimo.

No entanto, em alguns casos, apesar das boas notas, os filhos apresentam dificuldades em certos conteúdos curriculares específicos. Quando isso ocorre, algumas estratégias de "reparação" (NOGUEIRA, 2002, p. 154-167), visando remediar o problema, são utilizadas pelos pais, tais como: (a) recorrer à ajuda de parentes ou de outros professores para ajudar na realização das tarefas escolares (b) intensificar o estudo com o filho, inclusive nos finais de semana; (c) contratar aulas particulares e, por fim, mas não menos importante, (d) intervir diretamente estabelecendo contatos estreitos e frequentes com professores, coordenadores e diretores para solucionar o problema. Quanto a esse último ponto, tudo indica que o contato direto e constante com os professores dos filhos é, na visão desses pais, a melhor estratégia a ser adotada no caso de dificuldades escolares. Eles demonstram sentir-se muito à vontade para conversar com seus pares sobre a vida escolar dos filhos e no direito de interferir diretamente na escola; atitude que é, diga-se de passagem, bem recebida pelos pares, que reconhecem legitimidade nessa interferência.

Um último aspecto a ser dimensionado refere-se a um rompimento com uma tradicional clivagem de gênero nas práticas familiares de acompanhamento da vida escolar da prole. Embora a literatura sociológica mostre que a mãe exerce sempre um papel central nas práticas educativas de escolarização (VAN-ZANTEN, 1996; CHARLOT; ROCHEX, 1996; BOUNOURE, 1995), este estudo (na sua dimensão ampliada das 40 famílias estudadas) revela que essa regularidade é transgredida quando o progenitor docente é o pai. Em todos os casos investigados em que o pai (e não a mãe) exerce a docência como profissão, o trabalho de decidir, acompanhar e monitorar a vida e a trajetória escolar dos filhos é por ele liderado (NOGUEIRA, 2011).

O progenitor masculino da subamostra de sete famílias embora a esposa também possua diploma de ensino superior - toma para si as tarefas de acompanhamento das atividades escolares e as legitima no seio da família: "Eu sempre digo que a escola é comigo" ou "minha esposa não tem condição de ajudar os meninos, ela prefere deixar pra mim”. É ele, e não a mãe, que acompanha, cotidiana e intensamente, as tarefas escolares e as atividades extraescolares, assina os cadernos e os boletins e estabelece contatos diretos com a escola e com os professores dos filhos.

Essas são constatações preliminares que certamente demandam investigações mais aprofundadas, dado o número restrito de progenitores do sexo masculino no universo da pesquisa e a presença de apenas um 
sujeito na subamostra de sete famílias. Mas, desde já, é possível formular a hipótese de que a variável profissão docente se sobrepõe às variáveis "maternidade/paternidade" e "grau de escolaridade" no que concerne às condutas educativas dos pais.

\section{CONSIDERACְ̃̃ES FINAIS}

A pesquisa empreendida evidenciou as nuanças daquilo que se costuma denominar na Sociologia da Educação - de modo especial, em seus estudos sobre a relação família-escola - de "mobilização familiar" em prol da educação escolar dos filhos. Num universo de 40 famílias investigadas, cujos genitores pertencem a uma mesma categoria ocupacional, exercendo a docência no nível do Ensino Fundamental, foi possível identificar formas, de um lado similares, e, de outro, bastante distintas de mobilização familiar (NOGUEIRA, 2011, 2013).

Como recorte metodológico proposto para este trabalho, a análise das práticas educativas e das estratégias escolares de um grupo de sete famílias de pais professores - todos oriundos das camadas populares18 - ajuda-nos a compreender mais ampla e densamente os meandros do fenômeno das trajetórias escolares exitosas, comum em famílias de professores e constatado na literatura sociológica de apoio ao presente texto.

As ações parentais nas sete famílias que conduzem filhos e filhas ao sucesso escolar e, em consequência, a um percurso educacional longevo, podem ser "fruto de decisões explícitas e racionais, como também decorrem do processo de interiorização das regras do jogo social e revelam a intuição prática (o sens dujeu) que marca o bom jogador, o estrategista" (NOGUEIRA, 2002). A coordenação das estratégias conscientes ou inconscientes - é resultado de uma "intuição prática", marcada, sem dúvida, pela posse de conhecimentos sobre a escola e o sistema escolar e pelo desenvolvimento de disposições construídas nas experiências vividas hibridamente, como pais e professores. Ao que tudo indica, os pais professores, mesmo desfavorecidos pelas condições materiais, podem ser considerados, em relação às práticas educativas desenvolvidas, como "pais profissionais" (ESTABLET, 1987), pois, imersos na cultura escolar, adquiriram tacitamente o "senso do jogo" necessário ao desenvolvimento de estratégias que rentabilizam as atividades escolares e extraescolares da prole.

As ambições escolares nas famílias dos sete pais professores são, em certa medida, limitadas porque, mesmo que uma escolarização longa seja o ideal perseguido, as expectativas dos pais estão reduzidas 
pela consciência da fragilidade de suas condições objetivas, as quais se refletem na inevitabilidade de escolarizar os filhos na rede pública. A consciência de que estudar na escola pública traz consequências negativas para o percurso escolar posterior e dificulta o enfrentamento da alta competição no ingresso às universidades públicas faz com que esses pais optem por instituições de ensino superior particulares como uma estratégia para possibilitar aos filhos o prolongamento dos estudos e a garantia da posse futura de um diploma de Ensino Superior.

Além da redução relativa das expectativas escolares, a imagem da escola, construída a partir da própria experiência docente, baliza os processos de escolha do estabelecimento de ensino para os filhos e explica a desconfiança em relação à escola pública. Diante de uma "escolha" imposta por imperativos financeiros, as famílias elaboram uma classificação objetiva e simbólica das escolas públicas existentes no território onde residem e optam por aquela que melhor atende a seus objetivos: escola onde o pai/a mãe atuam profissionalmente, com bom clima escolar, em que diretores e professores fazem parte de sua rede de relacionamentos, escola com imagem pedagógica positiva entre os professores, são exemplos dos critérios de seleção por eles adotados.

Além disso, impelidos pela inevitabilidade de se servir da rede pública, esses pais se esforçam para atenuar as consequências "negativas" desse tipo de escolarização por meio de ações de "colonização" da escola. Eles desenvolvem estratégias para favorecer, ao máximo, a carreira escolar dos filhos, retirando do "inevitável" os maiores benefícios possíveis. O drama desses pais consiste em sua dupla consciência: a de que a escolarização na rede pública compromete indelevelmente a trajetória escolar dos filhos e a de que, impossibilitados de colocar os filhos na rede privada de ensino, precisam desenvolver estratégias antecipatórias e compensatórias que ofereçam a eles chances de sucesso e de longevidade escolar, neutralizando, ao menos em parte, essa desvantagem.

Nessas famílias, o grau de intensidade da "intervenção" dos pais é bastante forte e se desenvolve num contexto mais amplo de "colonização" da escola pública, cuja finalidade é a de prevenir e compensar as possíveis consequências negativas de uma escolarização na rede pública. Eles desenvolvem ações como escolher a turma, o professor e o lugar da criança na sala de aula ou, até mesmo, acompanhar de perto o dia a dia da escola, "exigir" a mudança de turma ou de professor. Para isso, utilizam a rede de relacionamentos construída no interior da escola, desenvolvendo contatos diretos e estreitos com a direção, com os professores e com os outros profissionais da escola. 
A rede de contatos construída pelos pais professores, ao longo da carreira docente e através de uma ampla imersão no universo escolar, constitui um "capital" bastante rentável, cuja posse possibilita a construção de "canais de confiança", por meio dos quais eles têm acesso a informações precisas e "quentes" sobre a vida escolar dos filhos e sobre o funcionamento geral da escola. Em suma, os contatos que os pais mantêm com diretores, coordenadores pedagógicos e professores são fundamentais, pois permitem que eles se beneficiem de informações privilegiadas e intervenham mais diretamente nas dinâmicas escolares.

Podemos, assim, concluir que os pais professores estão muito bem "equipados" para desenvolver estratégias eficazes no favorecimento da vida escolar dos filhos, mostrando-se "verdadeiros experts na arte de utilizar o sistema escolar", ao colocar "o aluno no centro de cálculos e estratégias que visam obter a pequena diferença que faz toda a diferença”" (DUBET, 1991, p. 365).

Por fim, se a influência da profissão docente na vida escolar dos filhos já é algo constatado neste e em outros trabalhos, como se viu na primeira seção, essa influência é ainda mais visível e pode ser observada em sua plenitude quando os pais professores escolarizam seus filhos na escola pública. São esses pais, que, desprovidos dos recursos econômicos necessários para incrementar a vida escolar dos filhos, procuram auferir, em grau máximo, os dividendos decorrentes da profissão em prol do êxito escolar da prole.

\section{REFERÊNCIAS}

ANDRADE, J. M. de. Profissão docente e escolarização dos filhos. 2006. 119 f. Dissertação (Mestrado em Educação) - Centro de Ciências da Educação, Universidade Federal de Santa Catarina. Florianópolis, 2006.

BALLION, R. Les consommateurs d'école. Paris: Stock, 1982.

BALLION, R. Le choix du collège: le comportement "éclairé" des familles. Revue Française de Sociologie, Paris: n. 27, p. 719-734, 1986.

BARG, K. The school success of teacher children. In: COLLOQUE FABRICATION FAMILIALE DE LA REUSSITE SCOLAIRE D'AJUSTEMENT AUX PUBLICS, 1, 2011, Annales Colloque Fabrication Familiale de la reussite scolaire. Paris: Université ParisDauphine, 2011. p. 132-154.

BATISTA, A. A. G. Professoras de Português, formação superior, matrimônio e leitura: um caso de estudo. In. PAIXÃO, L. P.; ZAGO, N. (Org.). Sociologia da Educação. Petrópolis: Editora Vozes, 2007. p. 79-109.

BERNSTEIN, B. Language and social class: a research note. British Journal of sociology, London, v. 3. n. 3, p. 163-176, 1960.

BERNSTEIN, B. Class, codes and control. London: Routledge and Kegan Paul, 1973. v. 1 
BOUNOURE, Annick. Parents de collégiens: conceptions et pratiques éducatives. Paris: Ens Editions, 1995

BOURDIEU, P. Le capital social : notes provisoires. In. BOURDIEU, P. Actes de la recherche en sciences sociales, Paris, n. 31., p. 2-3, jan. 1980.

BOURDIEU, P. A distinção: crítica social do julgamento. Tradução Daniela Kern e Guilherme J F. Teixeira. Porto Alegre: Zouk, 2008.

BOYER, R.; DELCLAUX, M. Des familles face au collége: portraits de groupes. Paris: Institut National de Recherche Pédagogique, 1995.

CHARLOT, B. e ROCHEX, J. Y. L' enfant- eleve: dynamiques familiales et experience scolaire. Familles et école. Lien Social et Politique. Paris, N. 35, p. 137-151, 1996.

COLEMAN, J. S. Social capital in the creation of human capital. American Journal of Sociology, Chicago. v. 94, p. S95-S120, 1988.

COLEMAN, J. S. Foundations of social theory. Cambridge, MA: Harvard University Press, 1990.

COSTA, A. L. da. Le réussite scolaire des enfants d'enseignants du primaire à la fin du collège : existe-t-il un " effet enseignant » ?. In: COLLOQUE FABRICATION FAMILIALE DE LA REUSSITE SCOLAIRE D'AJUSTEMENT AUX PUBLICS, 1, 2011, Paris. Annales Fabrication familiale de la resussite scolaire. Paris: Université Paris-Dauphine, 2011. p. 234-249.

DUBET, F. Les lycéens. Paris: Seuil, 1991.

DURU-BELLAT, M. Social inequalities in French secondary schools: from figures to theories.

British Journal of Sociology of Education, Londres, v. 17. n. 3, p. 341-350, 1996.

ESTABLET, R. L'école est-elle rentable? Paris: PUF, 1987.

GATTI, B.; BARRETO, E. de S. Professores do Brasil: impasses e desafios. Brasilia: UNESCO, 2009.

GEWIRTZ, S.; BALL, S.; BOWE, R. Markets, choice and equity in education. Buckingham/Philadelphia: Open University Press, 1995.

GISSOT, C.; HÉRAN, F.; MANON, N. Les efforts éducatifs des familles. Paris: Ministère de l'économie, Institut national de la statistique et des études économiques, 1994.

GOODSON, B. D. Parents as Teachers of Young Children: An Evaluative Review of Some Contemporary Concepts and Programs. In: HENDERSON, R.W. Bureau of Educational Personnel Development (DHEW/OE), Washington, 1975. Disponível em < http:/ / eric. ed.gov/?id=ED136967> . Acesso em: 14 fev. 2017

HATCHER, R. Class differentiationn in education : racional choices? British Journal of Education, Londres. v. 19, n. 1, p. 5-24, 1998.

INSEE-INSTITUT NATIONAL DE LA STATISTIQUE ET DES ÉTUDES ÉCONOMIQUES. Education et Families. EPCV, Paris: octobre, 2003.

$\mathrm{KOHN}, \mathrm{M}$. L. Class and conformity: a study in values. Chicago: University of Chicago Press, 1977.

LANGOUËT, G.; LÉGER, A. Public ou privée? Trajectoires et réussites scolaires, 2000. Disponível em < http:/ / alain-leger.mageos.com>. Acesso em: 29 jun. 2015.

LAŠEK, J.; Prospective teachers' attitudes to their profession. The New Educational

Review, Poland. v. 13, n. 3-4, p. 129-138, 2007. 
NERI, M. C. A nova classe média: o lado brilhante da base da pirâmide. São Paulo: Saraiva, 2011. NOGUEIRA, M. A. Famílias de camadas médias e a escola: bases preliminares para um objeto em construção. Educação e Realidade, Porto Alegre, v. 20, n. 1, p. 9-25, jan./jun. 1995.

NOGUEIRA, M. A. A construção da excelência escolar - um estudo de trajetórias feito com estudantes universitários provenientes das camadas médias intelectualizadas. In. NOGUEIRA, M. A, ROMANELLI, G., ZAGO, N. (Org.) Família \& Escola: trajetórias de escolarização em camadas médias e populares. Petrópolis: Vozes, 2000. p. 125-154.

NOGUEIRA, M. A. Elites econômicas e escolarização: um estudo de trajetórias e estratégias escolares junto a um grupo de famílias de empresários de Minas Gerais. 2002. 195 f. Tese (Concurso Público para Professor Titular) - Faculdade de Educação, Universidade Federal de Minas Gerais, 2002.

NOGUEIRA, M. A. A relação família escola na contemporaneidade: fenômeno social/ interrogações sociológicas. Análise social, Lisboa, v. 11, n. 176, p. 563-578, 2005.

NOGUEIRA, M. A. Família e escola na contemporaneidade: os meandros de uma relação. Educação e Realidade, Porto Alegre, v. 31, n. 2. p. 155-170, jul./dez. 2006.

NOGUEIRA, M. O. Pais professores e a escolarização dos filhos. 2011. 265 f. Tese (Doutorado em Educação) - Faculdade de Educação, Universidade Federal de Minas Gerais, Belo Horizonte, 2011.

NOGUEIRA, M. O. Efeito pai professor: o impacto da profissão docente na vida escolar dos filhos. Revista Brasileira de Educação, Rio de Janeiro, v. 18, n. 52, p. 65-79, 2013.

PASTORE, J., SILVA, N.V. Mobilidade social no Brasil. São Paulo: Macron Books, 2000.

POWER, S. et al. Education and Middle Class. Buckinghan/Philadelphia: Open University Press, 2003.

REIS, R. Os professores da escola pública e a educação escolar de seus filhos: uma contribuição ao estudo da profissão docente. São Paulo: Paulinas, 2006.

SANTANA, R. P. A. de. Professor da Escola Pública: onde estuda seu filho? A família do professor na escolha da escola dos filhos. Dissertação (Mestrado em Educação) - Faculdade de Educação, Universidade Católica de Salvador, Salvador, 2005.

SCALON, M. C. Mobilidade social no Brasil: padrões e tendências. Rio de Janeiro: Revan, 1999. SILVA, Pedro. Escola família: uma relação armadilhada: interculturalidade e relações de poder. Porto: Profedições, 2003.

SILVA, Pedro. Pais professores: reflexões em torno de um estranho objeto de estudo. Interacções, 2. 268-290, 2006a.

SILVA, Pedro. Escolas, famílias e lares. Um caleidoscópio de olhares. Interacções. N.2. 1-8, 2006b.

SILVA, Pedro. Pais professores: um retrato sociológico. In: SILVA, Pedro (Org.). Escola, família e lares: um caleidoscópio de olhares. Porto: Profedições, 2007a. p. 34-77.

SILVA, Pedro. Associações de pais, interculturalidade e clivagem sociológica: algumas questões. Revista eletrônica de educação, São Carlos: Universidade Federal de São Carlos, 2007b.

SINGLY, F. de. Le soi, le couple et la famille. Paris: Nathan, 1996.

SINGLY, F. de. O nascimento do indivíduo e seus efeitos na vida conjugal e familiar. In. PEIXOTO, C. E.; SINGLY, F de; CICCHELLI, V. (Org.). Família e individualização. Rio de Janeiro: FGV, 2000. p. 7-15

SINGLY, F. de. Sociologie de la Famille Contemporaine. Paris: Armand Colin, 2004. 
VAN ZANTEN, Agnès. L'école de la périphérie. Paris: Puf, 2001.

VAN ZANTEN, Agnès. Choisir son école: stratégies familiales et médiations locales. Paris: Presses Universitaires de France, 2009.

VAN ZANTEN, Agnès. A escolha dos outros: julgamentos, estratégias e segregações escolares. Tradução de Maria Amália de Almeida Cunha. Educação em Revista, Belo Horizonte, v. 26, n. 3, dez. 2010.

VIEIRA, C. R.; RELVAS, A. P. A(s) Vida(s) do Professor. Lisboa: Quarteto, 2005.

WILSON, S. M. The Secret Garden of Teacher Education. Education.msu.edu., Washington, v. 45. n. 11, may 1989. Disponível em: <http://education.msu.edu/ncrtl/pdfs/ $\mathrm{ncrtl} /$ craftpapers/cp892.pdf>. Acesso em: 10 maio 2015.

\section{NOTAS}

${ }^{1}$ A pesquisa contou com o apoio da Fundação de Amparo à Pesquisa do Estado de Minas Gerais (FAPEMIG).

${ }^{2}$ Foram distribuídos questionários a todos os professores das redes particular e pública do município que atendiam a três critérios: possuir diploma de ensino superior; lecionar no segundo segmento do ensino fundamental ( 6 ao $9^{\circ}$ ano) e ter filhos em idade escolar (6 a 14 anos), perfazendo um total de 130 casos. Desses, 114 questionários foram respondidos (101 mulheres e 13 homens), correspondendo a 86,3 \% dos professores do município que atendiam aos critérios estabelecidos. $\mathrm{O}$ tratamento dos dados redundou num retrato sociológico desse universo de professores, a partir do qual foi extraída uma subamostra de 40 famílias para a realização das entrevistas semiestruturadas.

${ }^{3}$ Embora se possa remeter aqui à noção de capital social desenvolvida por Bourdieu (1980), é, sobretudo, aquela adotada por Coleman $(1988,1990)$ que nos auxilia a compreender tal fenômeno, na medida em que faz apelo ao grau de integração dos indivíduos e à construção de relações, expectativas de reciprocidade e comportamentos confiáveis, constituindo-se não somente em um bem individual, mas também em um bem coletivo. Assim, por exemplo, contar com a "confiança" de seus pares professores e diretores escolares, converte-se, para os pais professores, em capital social.

${ }^{4}$ Foram utilizados dados estatísticos derivados da pesquisa Éducation et Famille (INSEE, 2003) do Ministério da Educação da França, publicada, em 2003, pelo Institut national de la statistique et des études économiques.

${ }^{5}$ Esse grupo majoritário que se serve da escola particular, com suas disposições e práticas educativas próprias, foi abordado em Nogueira (2011; 2013).

${ }^{6} \mathrm{O}$ termo "intervenção direta" é utilizado por Nogueira (2011) para definir o modo incisivo, intenso e direto de interferência dos pais professores na rotina escolar dos filhos, o que impacta fortemente as dinâmicas escolares em que os filhos-alunos estão envolvidos. Apesar de verificado no conjunto das 40 famílias investigadas, esse modo de intervenção mostra-se ainda mais expressivo no grupo das sete famílias estudadas neste texto.

${ }^{7}$ As famílias recompostas são constituídas por um cônjuge ou companheiro (a) e os filhos (as) vindos de casamentos anteriores.

${ }^{8}$ Do ponto de vista da renda, Neri (2011) define esse grupo social como sendo aquele composto por famílias cuja renda domiciliar se situa na faixa entre 2 e 8 salários mínimos aproximadamente. Mais recentemente, o relatório Definição da Classe Média no Brasil, 
elaborado pela Secretaria de Assuntos Estratégicos da Presidência da República com dados da PNAD, definiu como "classe C" famílias com renda domiciliar entre R \$1.100 a R\$3.875).

${ }^{9}$ Segundo informação da Prefeitura Municipal, não há estudo sobre a oferta de serviços e o acesso a eles e sobre a qualidade de vida da população nos diversos bairros da cidade. $\mathrm{O}$ documento "Itaúna em Dados", publicado pela Prefeitura em parceria com a Universidade de Itaúna, apresenta os dados gerais para a totalidade do município, sem especificação para as diferentes regiões da cidade. A classificação "bairro de classe média", "bairro nobre/bairro de elite" e "bairro em região de periferia/bairro de camadas populares" foi retirada dos discursos dos pais professores durante as entrevistas e confirmada por meio da observação direta dos bairros, durante a visita às moradias dos professores.

${ }^{10}$ Cada sociedade classifica e desclassifica as escolhas matrimoniais de homens e mulheres, as quais produzem casamentos homogâmicos ou heterogâmicos. O primeiro tipo referese a casamentos entre indivíduos posicionados no mesmo grupo social do ponto de vista cultural, social e econômico. Já no caso dos casamentos heterogâmicos, há disparidade entre os cônjuges no que se refere aos bens possuídos, seja no plano material, seja no plano simbólico. Assim, os casamentos ditos "regressivos" são heterogâmicos e acontecem nos casos em que um dos cônjuges se une a uma pessoa menos escolarizada e com ocupação de nível inferior à sua, rebaixando, em certa medida, as condições materiais e/ou simbólicas possuídas antes do matrimônio (SINGLY, 1996, 2000; BATISTA, 2007).

${ }^{11}$ Tem se tornado habitual, entre os pesquisadores, a afirmação de que, nas últimas décadas, dois tipos de trajetória escolar vêm se estruturando no Brasil: de um lado, frequência a escolas privadas nos Ensinos Fundamental e Médio e, depois, Ensino Superior público para os favorecidos - o chamado "circuito virtuoso"; e, inversamente, frequência a escolas públicas de Ensino Fundamental e Médio e, depois, faculdades particulares (em geral de baixa qualidade) para os mais desafortunados - o chamado "circuito vicioso" (NOGUEIRA, 2000).

12 "'Toda a relação da pequena burguesia com a cultura pode, de certo modo, ser deduzida da distância, muito marcada, entre o conhecimento e o reconhecimento, princípio da boa vontade cultural que toma formas diferentes segundo o grau de familiaridade com a cultura legítima, isto é, segundo a origem social e o modo de aquisição da cultura que lhe é correlativo" (BOURDIEU, 2008, p. 300).

13 No caso do único pai professor, observamos uma maior sintonia, no seio do casal, quanto a este ponto.

${ }^{14}$ Modelo educativo/socializador em que as práticas educativas familiares são fundadas no preceito da "comunicação aberta" e cujas decisões e julgamentos são elaborados com base nas qualidades psicológicas da pessoa e não no seu estatuto formal (de filho ou de pai). Constitui um sistema de socialização cuja educação dos filhos é prioridade familiar, e todos os comportamentos são discutidos e elaborados verbalmente, conduzindo a um tipo particular de "conversa" em que o conteúdo da comunicação são os juízos e as suas consequências, e as relações são construídas com base na negociação e no diálogo (BERNSTEIN, 1973).

${ }^{15} \mathrm{~A}$ dissonância entre as crenças e práticas educativas das mães professoras e de seus cônjuges parece ter relação com o fenômeno dos casamentos que se tornaram heterogâmicos. A aquisição, posterior ao casamento, de certo capital cultural/escolar possibilitado pela frequência ao Ensino Superior compromete a estabilidade da relação conjugal antes homogâmica e as mães precisam exercer um trabalho constante de manutenção das dinâmicas familiares e do matrimônio. No caso do pai professor, o fenômeno não se verifica porque o matrimônio ocorreu após a conclusão dos estudos universitários pelos dois cônjuges. Assim, a relação conjugal do pai professor e sua esposa é marcada por uma maior consonância entre crenças e práticas no tocante à educação dos filhos. 
${ }^{16}$ Carga horária de, no mínimo, 32 horas semanais, dividida quase sempre entre dois ou mais estabelecimentos de ensino.

${ }^{17}$ Em sua obra La Distinction: critique sociale du jugement, publicada originalmente em 1979, Bourdieu denomina o capítulo dedicado às classes populares de "A escolha do necessário" porque nele defende a tese de que é a lógica da necessidade que rege as condutas desse grupo social cujo estilo de vida é marcado pelas pressões materiais e pelas urgências temporais.

${ }^{18}$ Fenômeno cada vez mais frequente no quadro de professores da Educação Básica brasileira (GATTI; BARRETO, 2009).

Submetido: 26/08/2015

Aprovado: 08/04/2016

Contato:

Marlice Nogueira

Instituto de Ciências Humanas e Sociais (ICHS-UFOP)

Rua do Seminário, s/n, Centro Histórico

Mariana $|\mathrm{MG}|$ Brasil

CEP 35.420-000 
